\title{
Variety of Accident Causes in Construction Industry
}

\author{
Idris Othman ${ }^{1, *}$, Rafe Majid ${ }^{1}$, Hisham Mohamad ${ }^{1}$, Nasir Shafiq $^{1}$, and Madzlan Napiah ${ }^{1}$ \\ ${ }^{1}$ Universiti Teknologi PETRONAS, Civil and Environmental Engineering Department, 32610 Seri Iskandar, Perak, Malaysia
}

\begin{abstract}
Construction Industry is a high risk industry and widely recognised as one of most hazardous occupation in the world. The statistic of accidents in Malaysia give us a picture that Malaysian construction industry is one of the dangerous sectors that need a drastic overhaul from the current site safety practices. This paper describes a review of the accident causes occurred in construction site by various researchers during the last twenty (20) years. This paper discusses the accident causes in Malaysia construction works and entire world. The data collected shows that variety of accident causes in construction industry either in Malaysia or other country.
\end{abstract}

\section{Introduction}

In Malaysia, construction industry has an important role towards the development of the economy. Although the construction industry is not the main sector that contributes to Malaysia economy growth, it actually acts like a catalyst to other sector of economy such as education, finance, manufacturing and others. This actually means that the construction industry can be represented as one type of economic engine in Malaysia. Besides, the construction industries in Malaysia have an important role in order to produce wealth and improvise the quality of living in this country. In addition, from the establishment of this industry, there are many job can be offered to the citizen and this can help the growth of other industries in Malaysia.

Furthermore, not everyone recognizes that the construction industry in Malaysia is one of the critical sector that need a huge and fast service from the site safety practices. Mostly accidents are the result from combination of contributing causes and one or more unsafe acts and unsafe condition. The solution is to improve the safety at construction site we need to investigate the main causes of construction accidents. The knowledge that been obtained from the investigation can be utilized in formulating more conducive working conditions and environment at the construction site. (Abdul Rahim Abdul Hamid, Muhd Zaimi Abd Majid et al. 2008)

Moreover, many work-related risk factors can cause accidents on construction sites. The construction sector growth and economic trend at Malaysia as shown on Figure 1. As the number of construction sector growth is increase, the occurrence of hazard at the construction site might also increase. Furthermore, the established safety management which has been performed in other industries cannot be applied to construction industry in our country because of some condition. Therefore, in order to prevent the accidents from continuously occurred, the accident prediction model need to develop as prevention tool before construction works begin. According to Fajaruddin et. al., (2012), the accident prediction model has a potential to improve considerably the quality of engineering aspect of accident reduction and prevention in Malaysia.

${ }^{*}$ Corresponding author: idris_othman@utp.edu.my 


\section{MALAYSIA GDP FROM CONSTRUCTION}

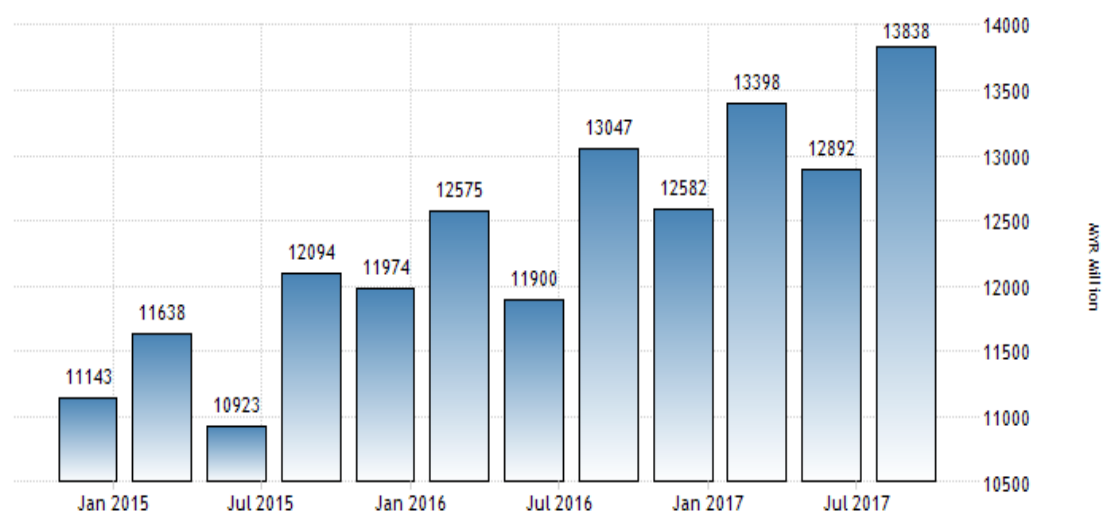

SOUPCE. TRADNGECONOWICS COU I DEPARTNENT OFSTATISTICS, MALAYSLA

Fig.1. Malaysia GDP from construction Industry.

\section{Theory of accidents causes}

An accident can be defined as an unplanned, undesirable, unexpected, and uncontrolled event. An accident does not necessarily result in an injury. It can be in term of damage to equipment and materials and especially those that result in injuries receive the greatest attention (Hinze, 1997). It is extremely difficult to talk about construction safety management in the absence of an understanding of the causes of accidents. Before one can embark on effectively and efficiently improving safety on the project site, one must first understand the theory of accident causation and prevention.

\subsection{The Domino Theory (Heinrich 1959)}

Heinrich (1959) was a pioneer in research on the conditions and circumstances that cause industrial accidents. He developed an accident causation theory known as the "domino theory."

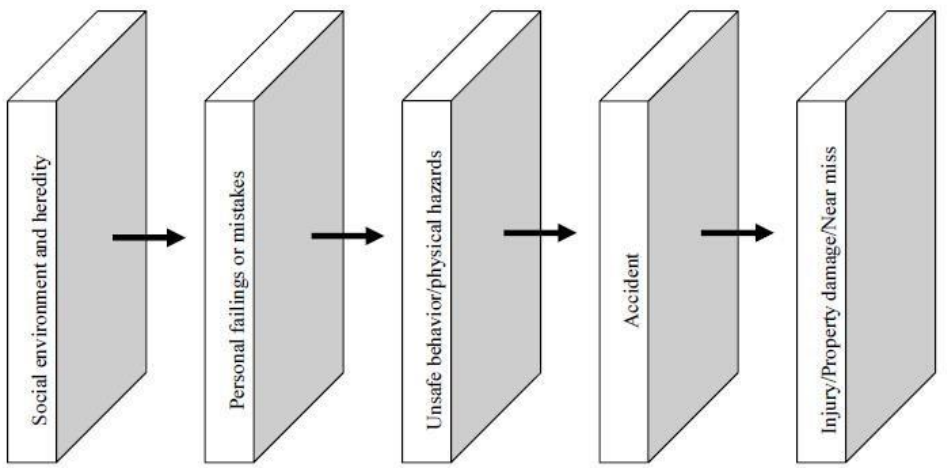

Fig. 2. Heinrich's Domino Theory (Heinrich, 1959). 
Heinrich's domino theory is comprised of five standing dominos that will fall one after the other if any domino falls (see Figure 2). An accident can be prevented only by removing one of the dominos preceding the accident. This interrupts the sequence and ensures that the accident does not happen.

The five sequential factors are as follows (Taylor, 2004):

i. Ancestry and social environment is the process of acquiring knowledge of customs and skills in the workplace. Lack of knowledge and skills required to perform tasks correctly and inappropriate social and environmental conditions will lead to the next domino: fault of person.

ii. Fault of person (carelessness) indicates negative features of a person's personality, although these unwanted characteristics might be acquired.

Carelessness will lead to the next domino: unsafe act/conditions.

iii. Unsafe act or mechanical or physical condition includes the errors and technical failures which cause the next domino: the accident.

iv. Accidents are caused by unsafe acts or conditions and subsequently lead to injuries

v. Injury is the consequences of the accident.

Heinrich's opinions were criticized for overemphasizing the immediate causes of accidents and neglecting an important aspect of accident causation and prevention: management practice (Hosseinian \& Torghabeh, 2012); however, Heinrich's research and work was the foundation for many other researchers. Heinrich's domino theory has been modified and updated over the years with greater emphasis on management as an original cause of accidents. The management-based theories define management as responsible for causing accidents, and they attempt to recognize failures within the management system (Liska, Goodloe, \& Sen, 1993).

\subsection{Multiple Causation Model (Petersen, 1971)}

The Heinrich domino theory states that an accident is the result of a single cause. Petersen (1971) developed a model based on management systems rather than individuals (See Figure 4). Petersen believed that there is more than one cause that contributes or leads to both the unsafe act, the unsafe condition, and, finally, the occurrence of an accident. Unlike in the simplified domino theory, there are causes and sub-causes that contribute to an accident. Through identification of these multiple contributing causes of an accident, the unsafe acts and unsafe conditions should be prevented.

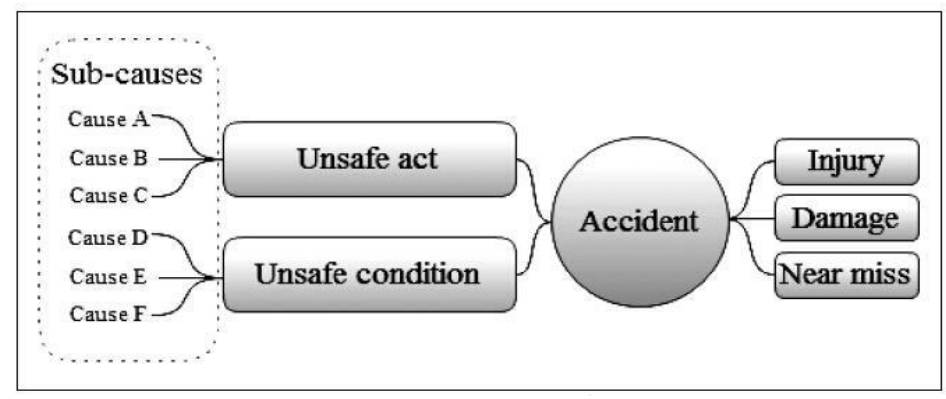

Fig.3. Multiple Causation Model (Petersen, 1971).

\subsection{Weaver's Updated Dominoes (Weaver, 1971)}

Weaver based his accident theory on Heinrich's domino theory, but added an emphasis on the role of the management system. Weaver revealed the role of operational errors by identifying the reasons why unsafe acts were allowed to persist and determining whether management had the safety knowledge to avoid the accident. Weaver set questions to clarify the underlying causes of the accident and to uncover why, if management had the knowledge of safety and relevant standards of the work, the worker continued to work in the unsafe condition. The answers to these questions can make clear the underlying operational errors that contributed to the accident (Abdelhamid, 2000). 


\subsection{Updated Domino Sequence (Bird and Loftus, 1974)}

Bird and Loftus (1974) also updated the domino theory to reflect the role of the management system in the dominobased model defined by Heinrich. The updated and modified domino model is illustrated in Figure 4 (Hosseinian \& Torghabeh, Major theories of Construction Accident Causation Models: A Literature Review, 2012).

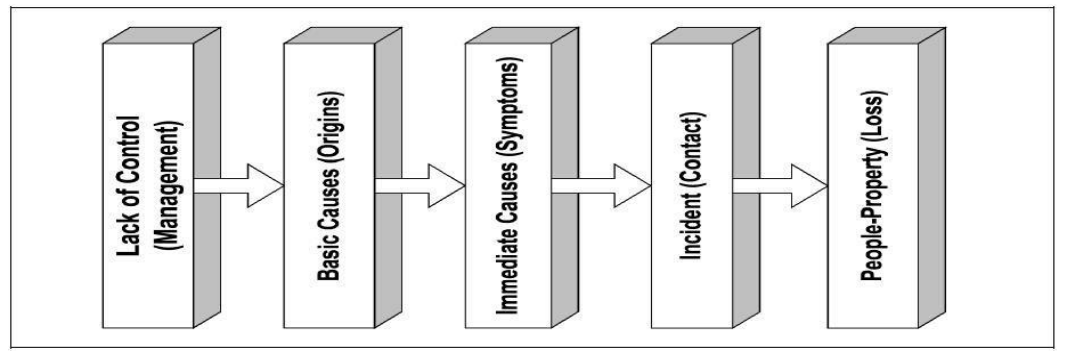

Fig.4. Updated Domino Sequence (Bird and Loftus, 1974).

Lack of control/management (inadequate program, inadequate program standard, inadequate compliance to standard) ii. Basic causes/origins (basic causes: 1-personal factors, 2-job factors) iii. Immediate causes/symptoms (sub-standard act and condition) iv. Incident (contact with energy and substance)

v. Loss (property, people, process)

In this representation, the "Basic Causes" domino refers to factors such as a lack of motivation to work safely, or uncorrected hazards - factors over which management has a great deal of control. Each of the dominos in this sequence serves as an opportunity for intervening action, but the greatest potential for accident prevention is the first domino. When the domino theory is presented in this manner, management control is seen as the most important factor in the accident sequence (Raouf, 1998).

\subsection{The 'Swiss Cheese' Model}

The 'Swiss Cheese' accident causation model was first developed by James Reason (1970-1977) as a linear accident causation model. It likens human systems to multiple slices of "Swiss_Cheese," stacked side by side, in which the risk of a threat becoming a reality is mitigated by the differing types of defenses that are "layered" behind each other. The theory is also widely used since it simply suggests that the organizations try to prevent accidents by defenses in order to prevent the risks and hazards from becoming losses (See Figure 5). 


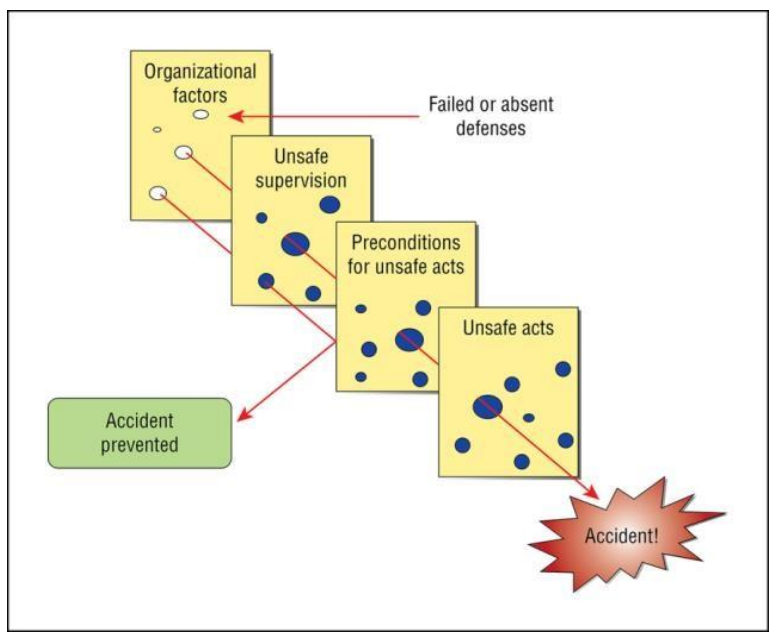

Fig. 5. 'Swiss Cheese' Model.

\subsection{Accident Proneness Theory}

Accident proneness theory maintains that within a given set of workers, there exists a subset of workers who are more likely to be involved in accidents. Researchers have not been able to prove this theory conclusively because most of the research work has been poorly conducted and most of the findings are contradictory and inconclusive (Raouf, 1998). This theory is not generally accepted. It is felt that if indeed this theory is supported by any empirical evidence at all, it probably accounts for only a very low proportion of accidents without any statistical significance.

\subsection{Wang's Theory of Accidents Causes and Prevention}

In Bird's representation, the "Basic Causes" domino refers to factors, such as a lack of motivation to work safely and other factors such as uncorrected hazards, over which management has a great deal of control. Each of the dominos in this sequence serves as an opportunity for intervening action, but the greatest potential for accident prevention is the first domino. When the Domino Theory is presented in this manner, management control is seen as the most important factor in the accident sequence (William A. Stanton, 1990).

By summarizing the two theories and interviews with safety expert, the new theory of accident causes and prevention was developed, shown in Figure 6.

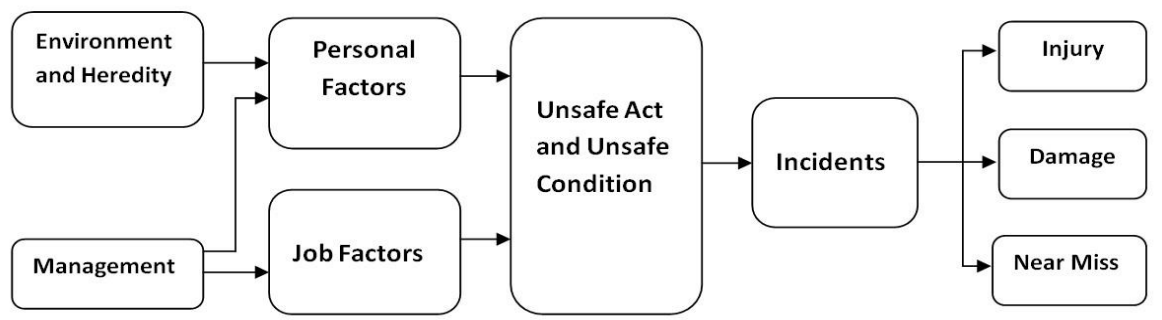

Fig. 6. Wang's Theory of Accidents Causes and Prevention.

The five important accidents causation factors are as following: 


\subsubsection{Environment and heredity}

A person's undesirable characteristics such as recklessness, stubbornness, greed, and bad temper can be passed along through inheritance or developed from their environment. In other words, such traits can be caused by nature or nurture. Environment and heredity could be defined as people's undesirable traits that are affected by the environment and can contribute to faults of person.

\subsubsection{Management}

Management is classified as the underlying cause. Management controls the factors that prevent incidents from happening, including safety planning and organizing.

\subsubsection{Personal factors}

These factors include personal undesirable characteristics such as bad temper, inconsiderateness, ignorance, recklessness, and other personal problems that are not work-related, such as mental problems, illness, bad attitude, and lack of understanding, ability or motivation.

According to Heinrich, natural or environmental flaws in the worker's family or life cause these secondary personal defects, which are themselves contributors to unsafe acts, or and the existence of unsafe conditions.

\subsubsection{Job factors}

These factors include all uncorrected hazards, such as acts of God, unsafe methods, job site conditions, unsafe equipment, inadequate work, normal or abnormal wear and tear, low-quality equipment, and bad design or maintenance.

\subsubsection{Unsafe acts and unsafe conditions}

These refer to the errors and technical failures that cause the accident and are the most significant factors that lead to accidents. Heinrich felt that unsafe acts and unsafe conditions were the central factor in preventing incidents, and the easiest causation factor to remedy, a process which he compared to removing one of the dominoes from the line.

All of the five causes were defined as the most important factors that result in construction accidents. Zero Incident Safety Management should be developed by eliminating these causes. To achieve this objective, the safety management factors should be identified based on the new theory of accident causes and prevention.

\section{Causes of accident in construction works}

From Principle of Construction Safety book byAllan St John Holt (2001), the causes of accident in construction works were divide by two i.e., primary causes and secondary causes(table1).

Table 1: Causes of Accident by Allan St John Holt (2001)

\begin{tabular}{|c|c|}
\hline Primary Causes & Secondary Causes \\
\hline $\begin{array}{ll}\text { 1. } & \text { Unsafe act } \\
- & \text { Working without authority } \\
\text { - } & \text { Failure to warn others of danger } \\
\text { - } & \text { Leaving equipment in a dangerous condition } \\
\text { - } & \text { Using equipment at the wrong speed } \\
\text { - } & \text { Disconnecting safety devices such as guards } \\
- & \text { Using equipment the wrong way or the } \\
- & \text { wrong tasks } \\
\end{array}$ & $\begin{array}{ll}\text { 1. } & \text { Management System pressures } \\
- & \text { Financial restrictions } \\
- & \text { Lack of commitment } \\
- & \text { Lack of policy } \\
- & \text { Lack of standards } \\
- & \text { Lack of knowledge and information } \\
- & \text { Restricted training and selection for tasks } \\
- & \text { Poor quality control systems resulting from } \\
& \text { the above }\end{array}$ \\
\hline
\end{tabular}




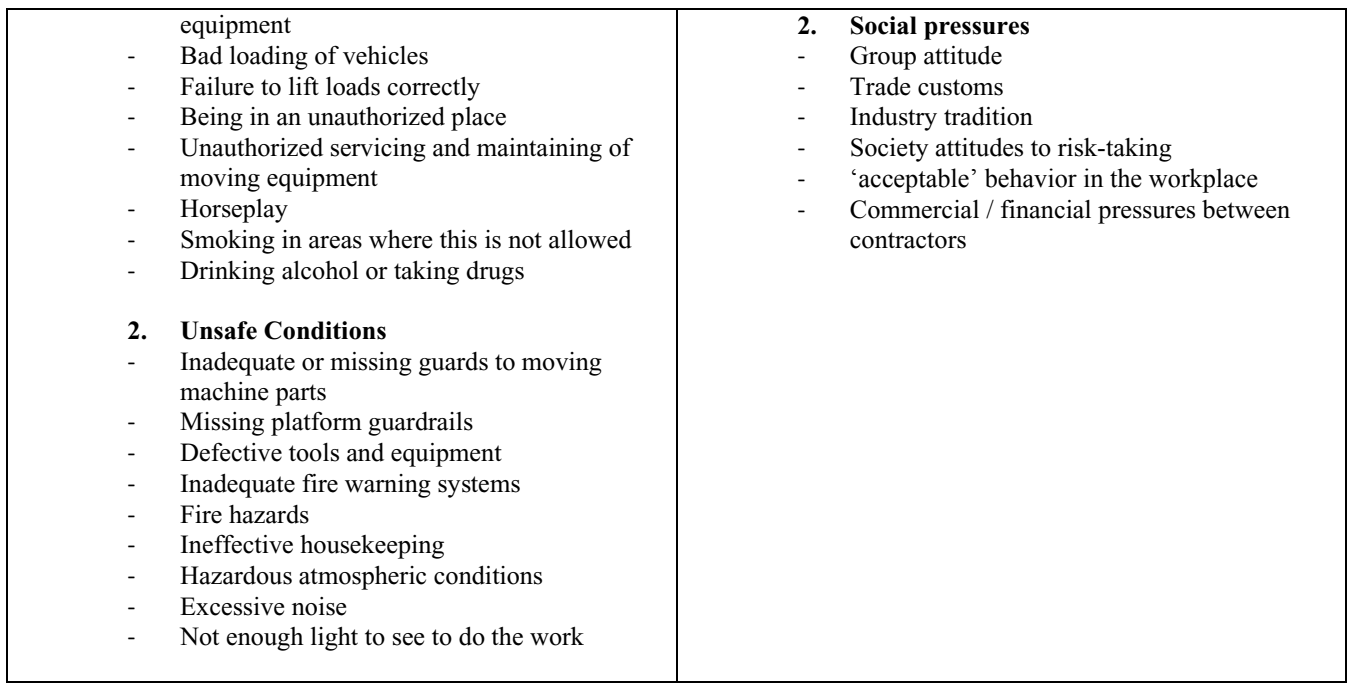

According to Kartam \& Bouz (1998), the worker turnover \& false acts, inadequate safety performance, improper cleaning \& unusable materials, destiny, low tool maintenance, supervisory fault and misplacing objects is the causes of accident at Kuawiti Construction.

According to Abdelhamid \& Everett (2000), classified the accident causes at United State of America (USA) construction works into human and physical factors (table 2).

Table 2: Causes of Accident by Abdelhamid \& Everett (2000).

\begin{tabular}{|c|c|}
\hline Human Factors & Physical Factors \\
\hline $\begin{array}{ll}\text { 1. } & \text { Failed to secure and warn } \\
\text { 2. } & \text { Failed to wear ppe } \\
\text { 3. } & \text { Horseplay } \\
\text { 4. } & \text { Operating equipment without authority } \\
\text { 5. } & \text { Operating at unsafe speed } \\
\text { 6. } & \text { Personal factor } \\
\text { 7. } & \text { Remove safety device } \\
\text { 8. } & \text { Serviced moving and energized equipment } \\
\text { 9. } & \text { Took unsafe position or posture } \\
\text { 10. } & \text { Used defective tool or equipment } \\
\text { 11. } & \text { Other unsafe action }\end{array}$ & $\begin{array}{ll}\text { 1. } & \text { Unsafe act of another person } \\
\text { 2. } & \text { Disregard known prescribed procedures } \\
\text { 3. } & \text { Defects of accident source } \\
\text { 4. } & \text { Dress or apparel hazard } \\
\text { 5. } & \text { Environmental hazard } \\
\text { 6. } & \text { Fire hazard } \\
\text { 7. } & \text { Hazardous arrangement } \\
\text { 8. } & \text { Hazardous method } \\
\text { 9. Housekeeping hazard } \\
\text { 10. Improper assignment of personnel } \\
\text { 11. Inadequately guarded } \\
\text { 12. Public hazard } \\
\text { 13. }\end{array}$ \\
\hline
\end{tabular}

According to Lubega et al (2000), the causes of accident in Uganda Construction works are Lack of awareness of safety regulations, Lack of enforcement of safety regulations, Poor regard for safety by people involved in construction projects, Engaging incompetent personnel, Non-vibrant professionalism, Mechanical failure of construction machinery/equipment, Physical and emotional stress and Chemical impairment.

Pipitsupaphol \& Watanabe (2000), study in Thailand was found the accident causes in Thailand construction works are Failure to use ppe, Improper loading or placement of equipment or supplies, Failure to warn co-workers or to secure equipment and Improper use of equipment. 
Tam et al (2004) study in China was found variety of accident causes in China Construction Works (25 causes) such as Poor safety awareness from top leaders, Lack of training, Poor safety awareness of project managers, Reluctance to input resources for safety, Reckless operation, Lack of certified skill labor, Poor equipment, Lack of first aid measures, Lack of rigorous enforcement of safety regulation, Lack of organizational commitment, Low education level of workers, Poor safety conscientiousness of workers, Lack of ppe, Ineffective operation of safetyregulation, Lack of technical guidance, Lack of strict operational procedures, Lack of experienced project managers, Shortfall of safety regulations, Lack of protection in material transportation, Lack of protection in material storage, Lack of teamwork spirits, Excessive overtime work for labor, Shortage of safety management manual, Lack of innovative technology and Poor information flow.

According to Goh, K. C., Goh, H. H., Omar, M. F., Toh, T. C., \& Zin, A. A. M. (2016), the causes of accidents at high rise building construction site were workers lack of training, Unskilled workers, Workers unsafe acts, Unsafe condition, Poor site safety management and less awareness of hazardous activities at work site.

\section{Causes Of Accident In Malaysia Construction Works}

According to Rahim, Hamid, Zaimi, Majid, \& Singh, ( 2008), the causes of accidents in Malaysia construction works were found to be similar to other country entire the world. However, some of the causes are low in frequency of occurrence. From research result, they found the main causes of construction accidents in Malaysia are the workers negligence, failure of workers to obey work procedures, work at high elevation, operating equipment without safety devices, poor site management, harsh work operation, low knowledge and skill level of workers, failure to use personal protective equipments and poor workers attitude about safety.

According to Heap Yih Chong \& Thuan Siang Low (2014), from SOCSO and DOSH report (2005-2009) found the causes of accident in Malaysia construction works are stepping on, striking against or struck by object, Falls, caught in between objects and overexertion or strenuous movements.

\section{Conclusion}

The literatures show that accident are caused by a wide range of factors, some of which are unsafe act, unsafe method, unique nature of the industry and site condition etc. Thus, the stakeholder likes employer, employees, suppliers, manufactures, governing agencies must cooperate together and try to prevent future construction accidents occurred.

\section{References}

1. https://radingeconomics.com/malaysia/gdp-from-construction (2017)

2. Hamid, M. K. B. G. Z. B. A., Kamar, M. Z. B. M. Z. A. H. B. A. R. K. A. B. M., \& Rahman, M. A. B. A. (2008). Safety in Malaysian Construction: The Challenges and Initiatives. Jurutera, (May 2008), 16-19.

3. A. Rahim, A. Hamid, M. Zaimi, A. Majid, \& B. Singh, (2008). Causes of Accidents At Construction Sites. Malaysian Journal of Civil Engineering, 20 (202), 242-259.

4. (Rahim, Hamid, Zaimi, Majid, \& Singh, 2008)(Mustakim et al., n.d.)(Hamid, Kamar, \& Rahman, 2008)

5. Kaichen goh, Hui hwanggoh, Mohd Faizal Omar, Tien Choon Toh and Abdullah Asuhaimi Mohd Zin, (2016). Accidents preventive practice for high-rise construction, MATEC Web of conferences 47, 04004(2016)

6. Y. C .Heap, S. L, Thuan (2014), Accidents in Malaysian Construction Industry: Statistical Data and Court Cases, International Journal of Occupational Safety and Ergonomics, 20 (3) 503-513, DOI: 10.1080/10803548.2014.11077064 
7. PRINCIPLES OF CONSTRUCTION SAFETY (book) - Allan St John Holt (2001), Blackwell science, inc, usa. Page 4-5 Isbn; 0-632-05682-7

8. N. Kartam, A.I. Flood, P. Koushki, (2000) Construction Safety in Kuwait:procedures, problem, and recommendation. Journal of Safety Science 36, pp. $163-184$.

9. H. Lubega, A. Kiggundu, B. M., D. Tindiwensi, (2000) An Investigation into the Causes of Accidents in the Construction Industry in Uganda - 2nd International Conference On Construction In Developing Countries: Challenges Facing The Construction Industry In Developing Countries, 15-17 Nov 2002, Botswana, pp112[online] Available http://buildnet.csir.co.za

10. T. Pipitsupaphol, T. Watanabe (2000) Identification of Root Causes of Labor Accidents in the Thai Construction Industry. Proceedings of the 4th Asia Pacific Structural Engineering and Construction Conference (APSEC 2000) 13-15 September 2000 Kuala Lumpur, pp193-202.

11. C.M. Tam, S.X. Zeng, Z. M. Deng, (2004) Identifying elements of poor construction safety management in China. Safety Science, 42 (2004) 569-586

12. K. C. Goh, , H. H. Goh, M. F. Omar, T. C. Toh, A. A. M. Zin, (2016). Accidents Preventive Practice for HighRise Construction. In MATEC Web of Conferences 47 EDP Sciences. 